\title{
DISEÑO E IMPLEMENTACIÓN DEL SISTEMA DE SEGUIMIENTO DE ESTUDIANTES Y TITULADOS DE LA UNIVERSIDAD DIEGO PORTALES
}

\section{Carolina Valenzuela, Sebastián Pérez ${ }^{1}$}

\section{RESUMEN}

Como parte de sus estrategias de aseguramiento de la calidad, la Universidad Diego Portales (UDP) instaló un sistema de seguimiento de estudiantes, cuyo objetivo es monitorear la evaluación sobre diversos aspectos de sus carreras y la universidad, así como conocer su experiencia universitaria. Este sistema está conformado por un conjunto de encuestas que los estudiantes responden en diversos momentos de su trayectoria: cuando ingresan a estudiar, a la mitad de su carrera, cuando están en proceso de titulación, y una vez titulados. Este sistema posibilita analizar cada momento de manera independiente y también un seguimiento longitudinal de los mismos estudiantes a lo largo de su carrera.

Palabras clave: seguimiento estudiantes, trayectoria académica, evaluación de estudiantes hacia carrera y universidad, factores asociados a progresión académica

\section{DESIGN AND IMPLEMENTATION OF A MONITORING SYSTEM FOR STUDENTS AND GRADUATES IN DIEGO PORTALES UNIVERSITY}

\section{ABSTRACT}

As part of its quality assurance strategies, Diego Portales University (UDP) has developed a system for monitoring students' evaluations in their undergraduate programs and the institution, as well as their university experience. The system is composed by a set of surveys that students answer at different stages of their academic progression: at the beginning, in the middle and at the end of their undergraduate programs as well as their first years in the labor market. This system allows UDP to analyze each of these moments independently and at the same time, studying the same students across their programs with a long-term focus.

Keywords: monitoring students, student progression, student's evaluation of academic programs and university, factors related to student progression 


\section{DISEÑO E IMPLEMENTACIÓN DEL SISTEMA DE SEGUIMIENTO DE ESTUDIANTES Y TITULADOS DE LA UNIVERSIDAD DIEGO PORTALES}

\section{Introducción}

La Universidad Diego Portales (UDP) -fundada en 1982- tiene por misión producir y certificar el saber disciplinario y profesional con sujeción a altos estándares de calidad, contar con comunidades académicas de alto desempeño y estrechamente vinculadas con el entorno, asegurar el pleno respeto por el pluralismo y la independencia crítica de sus miembros y promover: un diálogo informado, reflexivo, respetuoso y pluralista; el compromiso con el desarrollo del país; y una institucionalidad eficaz, eficiente y transparente.

Ha sido acreditada por la Comisión Nacional de Acreditación (CNA) en los años 2004 y 2008. En la última oportunidad fue acreditada por un periodo de cinco años, en las áreas de gestión institucional, docencia de pregrado y vinculación con el medio.

La UDP actualmente tiene 9 facultades, 32 carreras y programas de pregrado (27 diurnas y 5 vespertinas) y 69 programas de posgrado (2 doctorados, 22 magíster, 6 especialidades médicas, 25 diplomados y 14 postítulos). Se puede considerar como una institución de tamaño medio dentro del sistema universitario, con una matrícula de 12.651 alumnos en pregrado (en 2011), y una admisión de 1.391 estudiantes anuales en posgrado.

Como explicita su misión, la calidad y la diversidad son dos principios rectores del proyecto académico de la UDP. Con respecto a la calidad, posee una gran selectividad dentro del medio nacional (67\% de los estudiantes obtuvo sobre 600 puntos en la $\mathrm{PSU}^{2}$ de 2012; $6^{\circ}$ lugar en promedio PSU DEMRE ${ }^{3}$ en admisión 2012), compromiso con

Prueba de Selección Universitaria

Departamento de Evaluación, Medición y Registro Educacional. 
la acreditación institucional y de programas ( 5 años de acreditación institucional; $72 \%$ de estudiantes pertenece a carreras acreditadas), y destacadas posiciones en rankings (América Economía, Qué Pasa, QS, Scimago, entre otros).

En la actualidad, el 39\% de los estudiantes que ingresa a primer año son de la primera generación en su familia que accede a la universidad. El $40 \%$ del total estudia con Crédito con Aval del Estado (CAE) y el 32\% recibe becas internas o externas. Casi la mitad de la matrícula total de la universidad proviene del sistema escolar particular pagado (47\%) y la otra mitad, del particular subvencionado y municipal (38\% y $15 \%$, respectivamente).

En este contexto diverso y pluralista, monitorear la calidad del desempeño y la progresión de los estudiantes ha sido un eje de trabajo fundamental. El Sistema de Seguimiento de Estudiantes y Titulados que se presenta en este trabajo es parte de este esfuerzo, y junto con otras iniciativas -informe de calidad, jerarquización y calificación de profesores, acreditación, entre otros-, constituyen la cultura de monitoreo de la calidad que la universidad promueve institucionalmente.

\section{Aseguramiento de la calidad en la UDP}

La Dirección General de Pregrado y Calidad inició -en 2008- el diseño e implementación de un sistema de aseguramiento de la calidad, con estrategias de evaluación y seguimiento planificadas y sistemáticas. Estas están orientadas a asegurar y mejorar la calidad de la oferta académica de las unidades, sus académicos y docentes, y la progresión de los estudiantes en sus programas de estudio. Aun cuando algunas de las estrategias comenzaron antes de ese año -la instauración de la carrera académica en $2007^{4}$

4 Desde 2007 la UDP tiene carrera académica, que regula el ingreso, promoción y permanencia de los académicos. La calidad del cuerpo académico se fomenta por medio de la clara definición de las características esperadas en los profesores, por la fijación de incentivos que apunten al desarrollo de dichas características, y con procesos de evaluación continuos e imparciales, que sirvan tanto de instancias de rendición de cuentas como de monitoreo del desempeño de cada docente. Ver detalles de la carrera académica UDP en Ramírez (2008). 
o procedimientos formales para la actualización curricular desde 2004-, dicho sistema permitió ordenar diversas instancias en un mismo cuerpo con un objetivo más nítido.

Una referencia importante para el diseño del sistema de aseguramiento de la calidad institucional fue el conjunto de estándares de aseguramiento interno de calidad definidos por la ENQA (European Association for Quality Assurance in Higher Education). La ENQA establece siete estándares que las instituciones deben cumplir, como tener una política y procedimientos formales de aseguramiento de la calidad; procedimientos para aprobar, monitorear y revisar periódicamente sus carreras y programas, y tener procedimientos claros de evaluación de estudiantes (ENQA, 2007). Uno de los estándares está referido a que las instituciones cuenten con sistemas de información que permitan que las instituciones recojan, analicen y usen información relevante para la gestión efectiva de sus carreras, programas u otras actividades. Específicamente, este estándar define que una institución debe generar y utilizar información sobre la progresión de los estudiantes y titulación (success rates), empleo de sus titulados, satisfacción de los estudiantes con sus carrera y programas, efectividad de los profesores, perfil de la población estudiantil, disponibilidad de los recursos de aprendizaje y otros indicadores de desempeño importantes para la institución.

La universidad cuenta, desde 2004, con una serie de instrumentos y reportes de resultados difundidos internamente. Estos se refieren a la progresión de los estudiantes en sus carreras, la evaluación de estos hacia los diversos servicios, procesos académicos, sus carreras y la institución en general. Como una estrategia para sistematizar y reforzar dichos avances, en 2008 se inició el desarrollo de un sistema de información para el monitoreo de la calidad, el cual tiene tres herramientas principales: Informe de Calidad UDP (informe anual que sistematiza y analiza las principales áreas del quehacer de la universidad, principalmente por medio de indicadores cuantitativos); Sistema de Indicadores de Calidad en internet (información académica vigente e histórica de un conjunto de indicadores, mediante el acceso a una plataforma en línea) y el Sistema de Seguimiento de Estudiantes y Titulados. 


\section{Antecedentes para el diseño del Sistema de Seguimiento de Estudiantes y Titulados}

Para monitorear la progresión de los estudiantes en sus programas de estudio, la Dirección General de Pregrado y Calidad, con el apoyo del Centro de Políticas Comparadas de Educación, inició, en 2009, el diseño del Sistema de Seguimiento de Estudiantes y Titulados.

Las orientaciones para el diseño del sistema fueron principalmente dos. En primer lugar, este debía recoger la percepción de los estudiantes sobre el desarrollo de aspectos clave de la misión (interés por los problemas del país, pluralismo). En segundo lugar, debía estar alineado con las dimensiones de calidad del pregrado definidas por la universidad y ser útil para procesos de acreditación y actualización curricular, así como para la gestión de los directivos de las carreras.

Una primera etapa del diseño fue la revisión de experiencias de otras universidades en sistemas de seguimiento y la revisión de factores asociados a la trayectoria académica, tanto en aquellas que terminan en un grado académico como en las que no.

Las experiencias revisadas de otras universidades fueron COFHE (Consortium on Financing Higher Education); CIRP (Cooperative Institutional Research Program) de la Universidad de California, Los Angeles; CSEQ (The College Student Experiences Questionnarie Assessment Program) de la Universidad de Indiana y TESA (Teacher Education System of Assessment), de Lynch School of Education, de Boston College.

Un primer elemento que se destaca en la revisión de estas experiencias es la distinción que hacen del 'momento' o 'periodo' del ciclo de vida del alumno en que la información es recogida. Así por ejemplo, hay aspectos para monitorear en el momento en que el alumno 'ingresa' a la universidad, mientras 'progresa' en su carrera, cuando 'sale' de la universidad y cuando 'ingresa al mundo laboral'. El sentido longitudinal de la recolección de información permite monitorear no solo cada uno de esos momentos en sí mismo, sino 
también poder mirar los datos recogidos desde una mirada evolutiva de su cambio en el tiempo, por medio de un mismo conjunto de indicadores en diferentes momentos.

Con respecto a los factores determinantes en la trayectoria académica de los estudiantes, se revisaron numerosas publicaciones que mostraron la importancia de recoger datos sobre las características de los estudiantes que ingresan; antecedentes familiares, de estudios previos; sus características personales, como disposición hacia la carrera (motivación, hábitos de estudio, autoconfianza, expectativas); factores de contexto, como apoyo familiar, situación laboral del estudiante y financiamiento de sus estudios; factores de integración universitaria, como interacción con sus pares y profesores, participación en actividades extracurriculares, integración social y compromiso institucional; factores asociados a la deserción, como problemas vocacionales, de salud, económicos, responsabilidades familiares. En el caso de la inserción laboral, la revisión mostró la importancia de recoger información sobre la calidad del empleo de nuestros titulados, su satisfacción laboral, cuáles eran las variables significativas para su desempeño profesional y su evaluación sobre la formación profesional recibida.

\section{Diseño del Sistema de Seguimiento de Estudiantes y Titulados}

El Sistema de Seguimiento es un conjunto de encuestas aplicadas a los estudiantes en distintos momentos de su trayectoria académica y a titulados de pregrado. Su objetivo general es monitorear su percepción respecto a diversos aspectos de sus carreras y la universidad; caracterizar a los estudiantes que ingresan, indagar en las causales de deserción, y evaluar la calidad de la inserción laboral temprana de los titulados, entre otros aspectos, lo que permite informar la toma de decisiones de las unidades académicas y administrativas de la universidad.

Este sistema define cinco momentos específicos en los que se recoge la información de la trayectoria universitaria de los estudiantes: cuando ingresa a la universidad, cuando progresa o deserta de su 
carrera y cuando está en proceso de titularse, como asimismo los que corresponden a su trayectoria laboral temprana, a uno y tres años de haberse titulado de su carrera. Estos momentos permiten un análisis de los estudiantes en cada hito y también un análisis longitudinal de seguimiento de cohortes.

Cada uno de los cinco momentos de la trayectoria de un estudiante tiene asociado un instrumento de recolección de información, tal como se muestra en el siguiente gráfico:

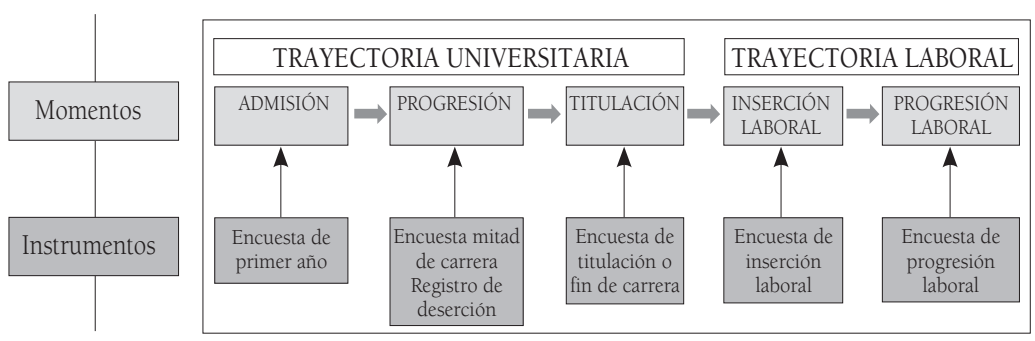

Gráfico 1. Diseño del Sistema de Seguimiento de Estudiantes y Titulados

En la tabla a continuación se presentan los objetivos, población objetivo y condiciones de aplicación de cada instrumento.

Tabla 1: Instrumentos, objetivos, población objetivo y condiciones de aplicación del Sistema de Seguimiento de Estudiantes y Titulados

\begin{tabular}{|c|c|c|}
\hline \multicolumn{3}{|c|}{ Trayectoria universitaria } \\
\hline Instrumento & Objetivo & Población objetivo y condiciones de aplicación \\
\hline \multicolumn{3}{|c|}{ Admisión } \\
\hline $\begin{array}{l}\text { Encuesta de } \\
\text { primer año }\end{array}$ & $\begin{array}{l}\text { Recoger información sobre las características } \\
\text { de los estudiantes al ingresar a la universidad, } \\
\text { en términos de: nivel socioeconómico } \\
\text { y cultural de su familia, antecedentes } \\
\text { académicos, disposición hacia los estudios, } \\
\text { motivaciones, expectativas académicas y } \\
\text { evaluación de su carrera y la universidad, } \\
\text { entre otros aspectos. }\end{array}$ & $\begin{array}{l}\text { Se aplica a todos los estudiantes nuevos, en febrero } \\
\text { y marzo de cada año. La encuesta se responde a } \\
\text { través de una página web. Contestarla es requisito } \\
\text { para la apertura de la cuenta en el portal web de } \\
\text { la universidad. Se comenzó a aplicar en } 2010 .\end{array}$ \\
\hline \multicolumn{3}{|l|}{ Progresión } \\
\hline $\begin{array}{l}\text { Encuesta } \\
\text { de mitad de } \\
\text { carrera }\end{array}$ & $\begin{array}{l}\text { Recoger información sobre la experiencia } \\
\text { universitaria de los estudiantes; } \\
\text { su integración social e institucional, la } \\
\text { relación con sus profesores, su evaluación } \\
\text { de los profesores, cursos, actividades } \\
\text { extraprogramáticas, entre otros. }\end{array}$ & $\begin{array}{l}\text { Se aplicará a todos los estudiantes matriculados } \\
\text { cuando hayan cursado la mitad de los ramos de su } \\
\text { plan de estudios, en noviembre-diciembre de cada } \\
\text { año. La encuesta se responde a través de una página } \\
\text { web. Se comenzará a aplicar en } 2012 \text {. }\end{array}$ \\
\hline
\end{tabular}




\begin{tabular}{|c|c|c|}
\hline $\begin{array}{l}\text { Registro de } \\
\text { deserción }\end{array}$ & \begin{tabular}{|l|} 
Recoger las causas por las cuales un \\
estudiante renuncia, suspende o anula el \\
semestre. Se le pregunta al estudiante si su \\
solicitud es por problemas vocacionales, y \\
qué opina de su carrera y la universidad.
\end{tabular} & $\begin{array}{l}\text { Los estudiantes que solicitan renunciar, suspender } \\
\text { o anular su semestre deben hacerlo a través del sitio } \\
\text { web de la universidad, y contestar una encuesta } \\
\text { con las causales asociadas a su decisión. } \\
\text { Asimismo, un directivo de la carrera debe reportar } \\
\text { las causales de deserción de los que renuncian a } \\
\text { la carrera, anulan el semestre o suspenden sus } \\
\text { estudios }\end{array}$ \\
\hline \multicolumn{3}{|c|}{ Proceso de titulación } \\
\hline $\begin{array}{l}\text { Encuesta de } \\
\text { titulación o } \\
\text { fin de carrera }\end{array}$ & $\begin{array}{l}\text { Recoger información sobre la experiencia } \\
\text { universitaria de los estudiantes, su } \\
\text { evaluación de sus cursos, profesores, } \\
\text { compañeros, servicios y otros aspectos } \\
\text { como sus expectativas académicas y opinión } \\
\text { general sobre su carrera y la universidad. }\end{array}$ & $\begin{array}{l}\text { Se aplica a todos los estudiantes que inician } \\
\text { sus trámites de titulación. Las respuestas son } \\
\text { vía el portal web de la universidad. Contestarla } \\
\text { es requisito para la titulación. Esta encuesta se } \\
\text { comenzó a aplicar el segundo semestre de } 2010 .\end{array}$ \\
\hline
\end{tabular}

\begin{tabular}{|c|c|c|}
\hline \multicolumn{3}{|c|}{ Trayectoria laboral } \\
\hline Instrumento & Objetivo & Población objetivo y condiciones de aplicación \\
\hline \multicolumn{3}{|c|}{ Inserción laboral } \\
\hline $\begin{array}{l}\text { Encuesta de } \\
\text { inserción } \\
\text { laboral }\end{array}$ & \begin{tabular}{|l|} 
Recoger información sobre la trayectoria \\
y situación laboral actual de los titulados, \\
su satisfacción laboral, las habilidades \\
relevantes requeridas en su trabajo, \\
evaluación de su carrera y la universidad, \\
sus estudios de posgrado y expectativas \\
con respecto a ellos y demandas de \\
servicios hacia la institución.
\end{tabular} & $\begin{array}{l}\text { Se aplica a los estudiantes de una muestra de } \\
\text { carreras, un año después de haber obtenido su } \\
\text { título profesional o licenciatura. Es una encuesta } \\
\text { telefónica efectuada en octubre y noviembre } \\
\text { de cada año, por una empresa externa a la } \\
\text { universidad. Se comenzó a aplicar en } 2009 .\end{array}$ \\
\hline \multicolumn{3}{|c|}{ Progresión laboral } \\
\hline $\begin{array}{l}\text { Encuesta de } \\
\text { progresión } \\
\text { laboral }\end{array}$ & $\begin{array}{l}\text { Recoger información sobre la trayectoria, } \\
\text { situación laboral actual de los titulados } \\
\text { y percepción de avance con respecto al } \\
\text { momento de titulación, su satisfacción } \\
\text { laboral, las habilidades relevantes } \\
\text { requeridas en el trabajo actual, } \\
\text { evaluación de su carreray la universidad, } \\
\text { sus estudios de posgrado y expectativas } \\
\text { con respecto a ellos y demandas de } \\
\text { servicios hacia la institución. }\end{array}$ & $\begin{array}{l}\text { Se aplica a los estudiantes de una muestra de } \\
\text { carreras, tres años después de haber obtenido su } \\
\text { título profesional o licenciatura. Es una encuesta } \\
\text { telefónica efectuada en octubre de cada año, } \\
\text { por una empresa externa a la universidad. La } \\
\text { cohorte que responde esta encuesta es la misma } \\
\text { que respondió la encuesta de inserción laboral } \\
\text { dos años antes. Se comenzó a aplicar en } 2009 .\end{array}$ \\
\hline
\end{tabular}

En el contexto del Sistema de Seguimiento, un estudiante de pregrado contestaría una vez las encuestas; de primer año, de progresión y de titulación. Luego de obtener su título profesional o licenciatura, respondería las encuestas de inserción laboral y de progresión laboral en caso de que su cohorte de titulación esté seleccionada -una por medio- dentro de un plan de seguimiento. 


\section{Algunos resultados del Sistema de Seguimiento de Estudiantes y Titulados}

La Encuesta de primer año ha posibilitado identificar y monitorear aspectos sociales, culturales y económicos de importancia en el desempeño inicial temprano, posible deserción y experiencia universitaria en general. Del mismo modo, este instrumento ha registrado diferencias significativas entre unidades -facultades y carreras- en cuanto a sus perfiles y desafíos. Por ejemplo, ha constatado que el 39\% de los estudiantes que ingresó a la universidad en 2012 -de un total de 2.787 estudiantes-, son primera generación universitaria (el padre y la madre no tienen estudios universitarios, aunque sean incompletos, y a lo más tienen educación técnica completa) y un 19\% son primera generación en educación superior (es decir, que el padre y la madre no tienen estudios universitarios o técnicos, aunque sea incompletos, y como máximo tienen enseñanza media completa). También ha identificado diferencias entre carreras, con variaciones desde un $19 \%$ a un $89 \%$ de estudiantes primera generación universitaria, y desde un $5 \%$ a un $67 \%$ de estudiantes primera generación en educación superior.

El registro de deserción nos ha permitido corroborar la evidencia ya disponible, que la mayor proporción de estudiantes (46\%) que renunciaron a la universidad -en el $2^{\circ}$ semestre de $2011-$ lo hizo por motivos vocacionales.

Por su parte, de los 1.463 estudiantes que respondieron la encuesta de titulación -aplicada en 2011-un 40\% afirmó no haber tenido mayores dificultades mientras estudió en la universidad. Las principales dificultades de los que sí dicen haberlas tenido (60\%) fueron: económicas (26\%), responsabilidades familiares que obstaculizaron los estudios (18\%), académicas por la mala base del liceo o colegio (14\%) y de salud (14\%). Asimismo, un 93\% afirmó estar de acuerdo o muy de acuerdo con haberse sentido integrado con sus compañeros y un $83 \%$ que existía una relación de cooperación entre ellos. 
Con respecto a la evaluación de sus profesores durante la carrera, la gran mayoría afirmó que, en general, tenían un excelente manejo de los temas enseñados (91\%), enseñaban con claridad la materia (85\%), se preocupaban por su aprendizaje (78\%), utilizaban metodologías apropiadas en el desarrollo de la clase (76\%), y promovían el pluralismo mostrando distintas visiones con respecto a un tema (70\%). Un último aspecto que destaca de los resultados es la confianza con que los titulados enfrentan el mundo laboral: un $86 \%$ de los estudiantes en proceso de titulación afirmó sentirse suficientemente o muy preparado para enfrentar el mundo del trabajo.

Finalmente, la Encuesta de inserción y progresión laboral a titulados que llevan uno o tres años en el mercado del trabajo -considerado los seguimientos de 2010 y 2011, con un total de 1.014 encuestados- muestra buenos niveles de empleabilidad de los titulados de la universidad. Por ejemplo, $97 \%$ ha trabajado en forma remunerada desde que se tituló, el tiempo promedio en encontrar su primer trabajo fue de 2,8 meses, y presentan un buen grado de satisfacción con su trabajo actual ( $90 \%$ pone nota 5 o más en escala de 1 a 7 ) y evaluación de su carrera (91\% pone nota 5 o más en escala de 1 a 7 ).

\section{Logros y desafíos del Sistema de Seguimiento}

El diseño del Sistema de Seguimiento a Estudiantes y Titulados generó importantes logros para el monitoreo de la calidad y también desafíos que se deberán asumir en el corto plazo.

Un primer logro del sistema es posibilitar una mirada longitudinal de la trayectoria de los estudiantes. En general, esta se percibía como compartimientos separados entre sí: admisión, titulación, inserción laboral. Este sistema permitió reforzar el concepto de seguimiento de cohortes no solo respecto de retención o tasas de titulación, sino también de otros aspectos, como la percepción que los estudiantes tienen de su carrera desde que ingresan a la universidad, se titulan e ingresan al mercado laboral.

Tener una buena caracterización de los estudiantes (socioeconómica, hábitos de estudio y problemas vocacionales, 
autoconfianza, entre otros) ha sido otro logro destacado del sistema. Esta mejor caracterización no solo ha permitido identificar los grupos de estudiantes más vulnerables y cómo se distribuyen en las distintas carreras, sino también monitorear el cumplimento de la misión institucional en sus ejes de pluralismo y de promoción de la movilidad educacional.

Un logro relevante del sistema fue haberse alineado con las necesidades de las carreras. Los resultados de las encuestas han sido insumos para los procesos de acreditación y de actualizaciones curriculares de carreras y para la gestión de los directivos de la carrera. Sin embargo, es necesario avanzar en el uso más sistemático de los resultados de este sistema.

Con respecto a los desafíos pendientes, es posible apreciar al menos dos. En primer lugar, es necesario avanzar -por medio de estudios y análisis multivariados- en la identificación de los factores asociados a trayectorias "exitosas" y "no exitosas", cimentando las bases para el diseño de sistemas de alerta e intervención para, por ejemplo, disminuir la deserción o mejorar la titulación en tiempo oportuno. Otra línea de estudios multivariados para desarrollar -la cual está estrechamente vinculada a la misión institucional-, es en qué medida la formación académica y profesional de la universidad logra agregar valor y nivelar la cancha en cuanto a resultados académicos y de inserción laboral de estudiantes provenientes de diversos orígenes socioeconómicos.

El segundo desafío es profundizar la creación de instancias formales en que la información generada por este sistema alerte y articule estrategias de intervención en el nivel central y en las facultades para corregir resultados, tendencias o trayectorias problemáticas o indeseadas. Lo anterior requiere seguir progresando en la difusión del sistema dentro de la universidad, así como diseñar instancias de gestión que identifiquen los problemas, unidades afectadas, planes de acción y monitoreo de resultados esperados. 


\section{Referencias bibliográficas}

ENQA (2007). Standards and Guidelines for Quality Assurance in the European Higher Education Area. Helsinki: ENQA.

De los Ríos, D. y A. Canales (2007). Factores explicativos de la deserción universitaria. Calidad en la Educación, № 26, pp. 173-201.

Donoso, S. y Schiefelbein, E. (2007). Análisis de los modelos explicativos de retención de estudiantes en la Universidad: una visión desde la desigualdad social. Estudios pedagógicos XXXIII, N 1: pp. 7-27.

Goldfinch, J. y M. Hughes (2007). Skills, learning styles and success of firstyear undergraduates. Active learning in higher education, $\mathrm{N}^{\circ} 8$, pp. 259-273.

Pascarella, E. y D.W. Chapman (1983). A multi-institutional path analytical validation of Tinto's model of college withdrawal. American Educational Research Journal, No 39(4), pp. 855-903.

Ramírez, M. (2008). Evaluación Académica en la Universidad Diego Portales. Calidad en la Educación (28), pp. 109-131. 